\title{
Effect of Premedication and General Anaesthesia on Arterial Blood Gases
}

\author{
A. J. S. GARDINER,* M.B., CH.B. ; K. N. V. PALMER, † M.A., M.D., M.R.C.P. \\ With the TeChnical Assistance of Miss M. H. MCGREGOR, M.s.c.T.
}

Brit. med. 7., 1964, 2, 1433-1434

Hypoxaemia persisting for many hours occurs after minor surgical procedures under general anaesthesia, and this arises whether breathing is spontaneous or is controlled during the anaesthetic (Nunn and Payne, 1962 ; Conway and Payne, 1964). A transient increase in the carbon-dioxide tension of the arterial blood after the operation, indicating impaired alveolar ventilation, has also been observed when breathing is spontaneous but not when it is controlled (Dundee, 1952; Hobsley, 1963). However, hypoxaemia without hypercapnia has been found after minor operative procedures (Nunn and Payne, 1962), and this is a constant feature for many days after major abdominal operations (Palmer and Gardiner, 1964a). In the latter instance it arises as a result of disturbances in the normal ventilation/perfusion relation within the lung secondary to impairment of pulmonary mechanical function as a result of the operation (Palmer and Gardiner, 1964b). The observation that patients developed hypoxaemia after atropine and before the operation suggested that premedication might be of importance in the development of hypoxaemia (Tomlin et al., 1964). There are therefore three possible factors in the production of post-operative hypoxaemia : premedication, the depressant effect of the anaesthetic on respiration, and impaired pulmonary mechanical function after the operation.

We have investigated the effect on arterial blood gases of atropine and papaveretum with scopolamine given for premedication, and of general anaesthesia in two groups of patients: one having a brief anaesthetic for carotid angiography, the other a longer anaesthetic for various minor surgical procedures.

The nature of the investigation was explained to the patients beforehand and their ready co-operation obtained.

\section{Method}

Thirty-one patients were studied. Eighteen (13 men and 5 women) had carotid angiography (group A). Their mean age cardio-respiratory disease, none was obese, and their general health was satisfactory. Control blood samples were obtained, with the patients semirecumbent, by percutaneous arterial puncture from the brachial or femoral artery into a $10-\mathrm{ml}$. heparin-lubricated syringe. The blood was allowed to fill the syringe under its own pressure for one to two minutes, and during this period the patient was encouraged to relax and breath naturally. This procedure was repeated 30 minutes after premedication. The patients in group A were given 0.6 $\mathrm{mg}$. of atropine by intramuscular injection. Those in group B were given $15 \mathrm{mg}$. of papaveretum and $0.3 \mathrm{mg}$. of scopol-. amine by the same route.

Anaesthesia was the same in both groups. This consisted of thiopentone intravenously (200-400 mg.) followed by suxamethonium to facilitate intubation and a nitrous-oxide/ oxygen mixture with added halothane breathed through a Magill circuit. Further arterial blood samples were obtained 15 minutes after the completion of the anaesthesia, by which time the patients undergoing carotid angiography were awake and alert while those undergoing other minor surgical procedures were awake but drowsy.

\section{Results}

All the control arterial-blood measurements were within the normal range in both groups (see Table and Chart). The normal range is slightly lower in the semirecumbent than in the vertical position. No significant change occurred in any of the mean values after premedication, whether with atropine or with papaveretum and scopolamine. After the operation no significant change occurred in the mean blood gases after carotid angiography, and in particular there was no evidence of hypoxaemia : 15 minutes after the other surgical procedures, however, there was significant hypoxaemia, the mean arterial oxygen tension being $83.2 \mathrm{~mm}$. Hg (S.D. = 12.38) compared with a control mean arterial oxygen tension of $93.0 \mathrm{~mm}$. $\mathrm{Hg}$ (S.D. =9.44) $(0.05>\mathrm{P}>0.02)$. There was no evidence of

Effect of Premedication and General Anaesthesia on Arterial Blood Gases

\begin{tabular}{|c|c|c|c|c|c|c|c|c|c|}
\hline & & \multicolumn{4}{|c|}{ Group A, 18 Patients undergoing Carotid Angiography } & \multicolumn{4}{|c|}{ Group B, 13 Patients undergoing Other Surgical Procedures } \\
\hline & & $p \mathrm{H}$ & $\mathrm{SaO}_{2}(\%)$ & $\mathrm{PaO}_{2}(\mathrm{~mm} . \mathrm{Hg})$ & $\mathrm{PaCO}_{2}(\mathrm{~mm} . \mathrm{Hg})$ & $p \mathrm{H}$ & $\mathrm{SaO}_{2}(\%)$ & $\mathrm{PaO}_{2}$ (mm. $\mathrm{Hg}$ ) & $\mathrm{PaCO}_{2}$ (mm. $\mathrm{Hg}$ ) \\
\hline $\begin{array}{l}\text { Control } \\
\text { Pre-med } \\
\text { Post-op. }\end{array}$ & $\begin{array}{l}. . \\
. .\end{array}$ & $\begin{array}{l}7.410(0.097) \\
7.399(0.052) \\
7.387(0.116)\end{array}$ & $\begin{array}{l}98.7(0.943) \\
97.3(1.414) \\
96 \cdot 2(2 \cdot 646)\end{array}$ & $\begin{array}{l}96.0(9.274) \\
94.9(10.099) \\
92.1(11.874)\end{array}$ & $\begin{array}{l}39.9(2.450) \\
38.3(3.020) \\
40.5(5.196)\end{array}$ & $\begin{array}{l}7.407(0.005) \\
7.415(0.066) \\
7.393(0.099)\end{array}$ & $\begin{array}{l}98.7(1.202) \\
97.3(0.835) \\
94.6(5.736)\end{array}$ & $\begin{array}{l}93.0(9.443) \\
93.0(7.294) \\
83.2(12.379)\end{array}$ & $\begin{array}{l}38.4(2.455) \\
37.6(3.063) \\
39.4(3.619)\end{array}$ \\
\hline
\end{tabular}

Values are expressed as the mean of the observations with the standard deviation of the observations in parenthesis.

was 48 years (range 21-70). Thirteen ( 9 women and 4 men) had various minor surgical procedures-for example, inguinal herniorrhaphy, appendicectomy, stripping and ligation of varicose veins (group B). Their mean age was 31 years (range 18-50). No patient in either group showed evidence of

* Clinical Research Fellow, Department of Medicine, University of Aberdeen.

t Senior Lecturer in Medicine, Department of Medicine, University of Aberdeen. hypercapnia, however, the mean arterial carbon-dioxide tension being $39.4 \mathrm{~mm}$. $\mathrm{Hg}$ (S.D.=3.62), and the mean arterial $\mathrm{pH}$ values were also normal.

\section{Discussion}

Unlike Tomlin et al. (1964), who found a mean oxygen saturation of $93.4 \%$ before operation in 24 patients pre- 
medicated with atropine compared with a mean oxygen saturation of $96.0 \%$ in 24 similar patients not given atropine, we did not find any evidence of a significant decrease in arterial oxygen saturation or tension after premedication with atropine or with papaveretum and scopolamine, and our findings are similar to those of Taylor et al. (1964), who failed to demonstrate a significant reduction in arterial oxygen saturation or tension after atropine in six patients who subsequently underwent uterine dilatation and curettage under general anaesthesia. Arterial desaturation was not detected

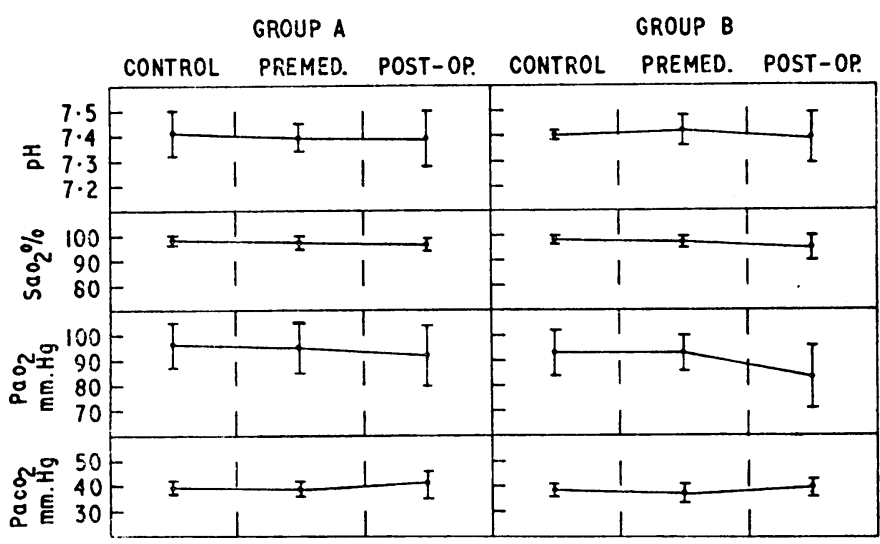

Systemic blood-gas tensions, $\mathrm{pH}$, and oxygen saturation in two groups of patients before and after premedication and anaesthesia. Group A, 18 patients undergoing carotid angiography. Group $\mathrm{B}, 13$ patients having other minor surgical procedures. Mean values shown for subjects in each group with two standard deviations at each period.

after atropine was given to healthy volunteers (Daly et al.; 1963), and, although increases in anatomical and physiological dead-spaces have been demonstrated after intravenous atropine in healthy volunteers, small increases in respiratory minute-volume maintained normal arterial carbon-dioxide tension levels, and no decrease in arterial oxygen tension or increase in alveolar-arterial oxygen tension gradients were observed (Nunn and Bergman, 1964). Thus atropine does not seem to cause hypoxaemia in fit young volunteers or in adults without cardio-respiratory disease about to undergo an operation, although they will almost certainly be anxious. It is not clear whether the respiratory effects of atropine differ in patients with chronic cardio-respiratory disease or whether any of those investigated by Tomlin et al. were in this category. Nevertheless, it seems established that in fit patients the recommendation of Tomlin et al. that premedication with atropine is not justified because of the development of hypoxaemia would not apply.

In the group of patients undergoing carotid angiography where the period of anaesthesia was short-about 15 minutes -no significant change in the arterial blood gases was observed after the procedure was complete, and, in particular, there was no evidence of hypoxaemia. Although Taylor et al. also found no evidence of hypoxaemia after the operation there was hypercapnia for half an hour afterwards. However, as all their patients had an operation in the lithotomy position, it seems that the position during the operation was a factor in the production of alveolar hypoventilation.

In our second group of patients who were undergoing various minor surgical procedures not only was the period of anaesthesia longer but the patients were drowsy after the operation, there was some post-operative pain, and many had had abdominal incisions, and it is likely that pulmonary mechanical function was thereby impaired. Nevertheless, although there was significant hypoxaemia, there was no evidence of overall alveolar hypoventilation, as the arterial carbon-dioxide tension level was normal. This suggests the presence of deranged ventilation/perfusion relations within the lung, and this has been shown to be present after partial gastrectomy when hypoxaemia without hypercapnia also occurs (Palmer and Gardiner, 1964b).

\section{Summary}

The effect of premedication and general anaesthesia was studied in 31 patients. Premedication with atropine or with papaveretum and scopolamine was not followed by a change from the control arterial blood measurements, and in particular there was no change in arterial oxygen saturation or tension, both values being directly measured. Eighteen of the patients underwent carotid angiography under general anaesthesia, breathing spontaneously, and no hypoxaemia or other change in the arterial blood measurements occurred in these afterwards, but transient hypoxaemia without hypercapnia was found in 13 patients after other minor operations which required a longer period of anaesthesia.

Our thanks are due to the surgeons and anaesthetists for their co-operation and for allowing us to examine their patients. Our thanks are also due to the Vaughan Hudson Clinical Trust and the Mary Kinross Clinical Trust for their generous help in the purchase of apparatus.

\section{REFERENCES}

Conway, C. M., and Payne, J. P. (1964). Lancet, 1, 12.

. Daly, W. J., Ross, J. C., and Behnke, R. H. (1963). f. clin. Invest., 42, 1083.

Dundee, J. W. (1952). Brit. med. f., 2, 893.

Hobsley, M. (1963). Ann. roy. Coll. Surg. Engl., 33, 105.

Nunn, J. F., and Bergman, N. A. (1964). Brit. F. Anaesth., 36, 68.

- and Payne, J. P. (1962). Lancet, 2, 631.

Palmer, K. N. V., and Gardiner, A. J. S. (1964a). Brit. med. F., 1, 347. (1964b). Thorax, in press.

Taylor, S. H., Scott, D. B., and Donald, K. W. (1964). Lancet, 1, 841.

Tomlin, P. J., Conway, C. M., and Payne, J. P. (1964). Ibid., 1, 14. 